\title{
ILUSÃO DE POVO AFRICANO: de organização da unidade africana a carta africana dos direitos e dos povos
}

\begin{abstract}
Aliu Gomes ${ }^{1}$
RESUMO: Este trabalho tem o objetivo de mostrar os caminhos percorridos pela Organização da Unidade Africana (OUA), que foi substituída pela União Africana em 9 de Julho de 2002 para alcançar um sistema de proteção africana dos direitos humanos e dos povos, através da Carta Africana dos Direitos e dos Povos, denunciando o uso dos princípios de soberania e não-ingerência como instrumentos para justificar crueldades. Os ditadores africanos, nas décadas de 60 e 70, adotaram uma política de massiva violação dos direitos humanos, acabando com a esperança de liberdade que o povo africano almejava com o fim da colonização. Os países desenvolvidos desejam que os países em desenvolvimento atinjam seus patamares em relação aos direitos humanos, direitos estes inseridos na Carta Africana dos Direitos e dos Povos.
\end{abstract}

Palavras-Chave: Soberania, Não ingerência, OUA, Carta Africana.

\section{THE ILUSION OF THE AFRICAN PEOPLE: FROM THE AFRICAN UNITY ORGANIZATION TO THE AFRICAN CHARTER OF PEOPLE'S AND RIGHTS}

Key-Words: Sovereignty, Non-interference, AUO, African Charter.

\begin{abstract}
The present work has the objective of showing the ways travelled by the Organization of African Unity (OAU), which has been replaced by the African Union in July, 9, 2002 to reach a African system of protection of human and people's rights, throught the African Charter of the Rights and the People's, denouncing the use of the principles of sovereignity and non-interference as instruments to justify cruelties. The african dictators, in the decades of the 60's and the 70's, adopted a policy of massive violation of human rights, ending the hope of freedom that the african people sought, with the end of the colonial period. The developed countries wish that the countries in development reach their own steps in relation to the human rights, rights which are inserted in the African Charter of the Rights and the People's.
\end{abstract}

\footnotetext{
${ }^{1}$ Acadêmico de Direito da Universidade Federal de Santa Maria.
} 


\section{1- INTRODUÇÃO}

O ser humano nasce para viver numa sociedade, com dignidade e com direitos iguais, respeitando as diferenças culturais, sociais e relacionando-se com espírito de solidariedade. Os direitos humanos passaram a ter grande importância a partir de herança histórica de grandes atrocidades ocorridas no mundo, principalmente na Segunda Guerra Mundial, que impossibilitava uma convivência digna dos seres semelhantes no ambiente comum. Em virtude dessas atrocidades, em meados do século XX, consolidam-se internacionalmente os direitos humanos, surgindo assim vários sistemas para proteção desses direitos.

Entretanto, é pertinente frisar que a Segunda Guerra Mundial simbolizou também uma ruptura em relação aos direitos humanos, significando no pós-guerra a esperança de reconstrução destes mesmos direitos. O massacre do nacional-socialismo de Hitler poderia ter sido evitado se existisse um sistema de proteção internacional dos direitos humanos como, por exemplo, a declaração da ONU.

Ao longo dos tempos, a definição de direitos humanos apresenta uma pluralidade de significados. No dizer de Flores (apud Piovesan, 2006, p. 6) ${ }^{2}$, os direitos humanos compõem a nossa racionalidade de resistência, na medida em que traduzem processos ou abrem e consolidam espaços de luta pela dignidade humana.

Ao lado do sistema normativo global, surgem sistemas regionais de proteção, que buscam internacionalizar os direitos humanos nos planos regionais, particularmente na Europa, América e África (cujo sistema africano será objeto de estudo nos títulos seguintes). Consolida-se, assim, a convivência destes sistemas regionais com o sistema global de ONU. Piovesan reafirma a posição de muitos autores, entre os quais Flores no que tange a convivência dos sistemas globais e regionais: "os sistema global e regional não são dicotômicos, mas complementares" (Piovesan, 2006, p.19) ${ }^{3}$. Portanto, (concluise) que os dois sistemas podem se complementar, desde que sejam contextualizados, respeitando assim os valores e costumes de cada sociedade.

\footnotetext{
2 PIOVESAN, 2006.

${ }^{3}$ Ibid.
}

(C) 2008. Departamento de Direito da UFSM. Todos os direitos reservados. 


\section{2- LIBERDADE UTÓPICA}

A declaração de 1948 inova a gramática dos direitos humanos, ao introduzir a chamada concepção contemporânea de direitos humanos, marcada pela universalidade e indivisibilidade destes direitos ${ }^{4}$.

Com a consolidação internacional dos direitos humanos e o surgimento dos sistemas regionais, em maio de 1963, quando 30 Estados Africanos assinaram a carta da OUA, foi discutida novamente a proposta para a Convenção Africana de Direitos Humanos. Para os governos africanos da época, a questão dos direitos humanos não era prioridade, ficando restrita a seminários, conferências e simpósios. Para grandes intelectuais da época, estes eventos não tinham resultados positivos, o que dificultava a mudança ${ }^{5}$.

Em setembro de 1979, a pedido de Assembléia Geral e da Comissão de Direitos Humanos da ONU e a convite do governo da Libéria, o Secretário-Geral da ONU organizou, em Monrovia, um seminário sobre o estabelecimento de comissões regionais de direitos humanos, com especial referência à África. A sua importante conclusão é a que sustenta que o princípio de não-ingerência nos assuntos internos de um Estado não deveria excluir a ação internacional, quando da violação dos direitos humanos. Não obstante, considerou que a função principal da comissão Africana de direitos humanos seria a de informar à população sobre seus direitos.

Mesmo com esta concepção inovadora dos direitos humanos, os Estados Africanos violavam tais direitos, baseados nos principio de soberania absoluta e nãoingerência, sem entender que a proteção dos direitos humanos não seria só um problema nacional, o que fortalece a idéia, no dizer de Piovesan $\left(2006\right.$, p.18) ${ }^{6}$, de que "a proteção dos direitos humanos não deve se reduzir ao domínio reservado do estado, porque revela tema de legítimo interesse internacional".

Para Schneider apud Piovesan (2006, p. 281)

Alerta que, em havendo mais de uma norma aplicável, em caso de violação dos direitos humanos, prevalecerá a norma mais favorável à proteção da vítima. Isso porque, no plano da

\footnotetext{
${ }^{4}$ Piovesan, p. 18 .

${ }^{5}$ ANDRADE, p.04

${ }^{6}$ Piovesan, 2006.

${ }^{7}$ Ibid.
}

(C) 2008. Departamento de Direito da UFSM. Todos os direitos reservados. 
proteção dos direitos humanos, há a intenção do direito internacional e do direito interno, implicando a prevalência da norma que melhor proteja o ser humano, tendo em vista a primazia da pessoa humana.

E ainda aponta a necessidade de revisão de noção tradicional de soberania absoluta do Estado, que passa a sofrer um processo de relativização, na medida em que são admitidas intervenções no plano nacional, em prol da proteção dos direitos humanos; isto é, transita-se de uma concepção "Hobbesiana" de soberania, centrada no Estado, para uma concepção "Kantiana" de soberania, centrada na cidadania universal e na cristalização da idéia de que o individuo deve ter direitos protegidos na esfera internacional, na condição de sujeito de direito.

Deste modo, seria o fim da era em que a forma pela qual o Estado tratava seus nacionais era concebida como um problema de jurisdição doméstica, decorrente de sua soberania $^{8}$.

Durante a década de 60 e 70, a maioria dos Estados Africanos tomou a sua independência e nasceu a esperança, por parte do povo, que, com o fim da colonização, estaria livre de todos os males da colonização e teria oportunidade de se autodeterminar, esperança que foi somente uma ilusão e que estava longe de ser a realidade almejada pelo povo africano 9 .

Segundo Andrade (2008 PP. 5-6) ${ }^{10}$ :

Havia, durante as décadas de 60 e 70, os sistemas políticos ditatoriais nos quais existia só um regime único e, provavelmente, aqueles que lutaram pela independência, passaram a governar e, agora no poder, não queriam a liberdade dos seus povos; não existiam mais respeitos aos direitos civis, políticos (liberdade de imprensa, associação) e a eleição. A vida passou a ter o valor que tinha na época da colonização, ou seja, aqueles que se submetiam ao regime militar tinham a vida preservada; casos contrários seriam torturados, juntamente com suas famílias, até a morte.

Então, na época, a idéia de igualdade já não existia no seio da sociedade africana, na qual os seres humanos tinham tratamentos desiguais e o papel do Estado, de proteger seus cidadãos, não existia mais, pois ele próprio passou a maltratá-los. Vale lembrar aqui o significado da palavra igualdade, na visão de Dallari (2004, p.16) ${ }^{11}$ ”A igualdade, significando que uma pessoa não vale mais do que outra ou uma não vale menos do que outra; mas vale salientar que cada ser humano tem sua individualidade, sua personalidade, seu modo próprio de ver e sentir as coisas".

Nessa época, os países africanos que mais sofriam com estas atrocidades cometidas pelos seus Estados levaram a queda de três ditaduras: a do Imperador Jean

\footnotetext{
${ }^{8}$ ANDRADE.p. 18

${ }^{9}$ ANDRADE 2008.

${ }^{10}$ Ibid.

${ }^{11}$ DALLARI, 2004.
}

(C) 2008. Departamento de Direito da UFSM. Todos os direitos reservados. 
Bokassa, da (República Centro-Africana), a do Presidente Nguéma Macias, da (Guiné Equatorial) e a do general Idi Amin Dada, da (Uganda) ${ }^{12}$.

Uma vez que os direitos humanos fundamentais são os mesmos para todos os humanos, continuarão existindo, mesmos para aqueles que cometeram crimes contra a humanidade. A maioria dos ditadores Africanos chegou ao poder através de guerras civis ou golpes de estado e, com isso, os direitos humanos perderam o seu significado, em detrimento do objetivo almejado pelos guerrilheiros. Observa-se que o que reina neste momento é egoísmo. Neste sentido, vale lembrar Dallari (2004, p.15) ${ }^{13}$, que preconiza que "o sucesso político ou militar de uma pessoa ou povo, bem como o prestigio social ou conquista de riquezas, não é válido ou merecedor de respeito, se for conseguido mediante ofensas à dignidade e aos direitos fundamentais dos seres humanos".

Nas constantes guerras civis, no Continente Africano, a vida passou a ter menos valor do que uma pedra preciosa, como no caso de Angola, que mergulhou em guerra durante quase três décadas, quando os diamantes e o petróleo eram vendidos para comprar armas para destruir a vida humana, que é um bem indisponível e inviolável. $\mathrm{Na}$ verdade, ninguém tem o direito de tirar a vida do outro, uma vez que nas constituições modernas, cada Estado positiva e dá maior destaque à proteção dos direitos fundamentais. Nesse sentido, segundo mesmo autor referido acima (2004, p.33) $)^{14}$, "nenhum homem inventa ou cria a vida e como não é capaz de criá-la e ninguém tem direito de tirá-la. Ela não é dada pela sociedade ou pelo governo e quem não é capaz de dar a vida então não tem direito de tirá-la".

Por outro lado, a vida é bem superior à pessoa humana e à pena de morte, que continua a existir em muitos países como nos EUA, na Arábia Saudita, na China, etc. É contraditório e imoral por estar desrespeitando um direito fundamental que é a vida humana. ${ }^{15}$

\footnotetext{
${ }^{12}$ ANDRADE.2008.p.7

${ }^{13}$ Dallari,2004

${ }^{14}$ Ibid

${ }^{15}$ DALLARI, 2004, p.8-12
}

(C) 2008. Departamento de Direito da UFSM. Todos os direitos reservados. 


\title{
3- O SISTEMA DE PROTEÇÃO AFRICANO E O PRINCÍPIO DE NÃO- INGERÊNCIA E SOBERANIA
}

Com o surgimento das Nações unidas, acentuaram-se os aspectos que limitariam a soberania, uma vez que ela hoje é subordinada à ordem jurídica internacional. Pode-se dizer que o desdobramento da soberania é o dever de não-ingerência na área da jurisdição exclusiva dos outros Estados e sua subordinação ao direito internacional. Assim sendo, a soberania é um feixe de competências que o Estado possui e que lhe é outorgado pela ordem jurídica internacional ${ }^{16}$.

No começo do século XXI, a sociedade internacional, definida pela interação cultural e ao avanço dos meios de informação, pelo processo de globalização econômica, as distâncias foram reduzidas e, portanto, não há como falar de soberania absoluta.

O conceito da soberania absoluta foi desenvolvido na época de formação dos Estados Nacionais, quando tudo girava em torno de Europa. Assim, nas décadas de 60 e 70, quando a maioria dos Estados Africanos começou a se formar, estes trataram a soberania no seu conceito tradicional, ou seja, como sendo absoluta, legitimando, assim, os atos cruéis cometidos naquele período, sustentando a tese que o problema tratava-se de questões domésticas baseado, assim, na soberania e não-ingerência ${ }^{17}$.

Como demonstra Andrade (2008 p.6) ${ }^{18}$ :

\begin{abstract}
Os princípios de não-ingerência nos assuntos internos e de respeito à soberania fizeram com que os direitos humanos não fossem o objeto da discussão por quase 20 anos nos órgãos da OUA. Desse modo, a OUA silenciava frente a grandes violações dos direitos humanos e realçava a tese de que se tratava de assuntos internos de cada Estado, sendo que o principio de nãoingerência e de soberania eram óbices para tal fim; ainda, não era a OUA um tribunal que pudesse julgar os seus membros por suas políticas internas.
\end{abstract}

Um dos casos que demonstram a ausência da OUA, diante de várias violações, ocorreu nos anos 70, quando da expulsão, de Uganda, pelo general Idi Amin Dada, dos britânicos de origem asiática e a expulsão do Gabão pelo presidente Omar Bongo, de cidadãos de Benin, ambos os atos reprovados pela comunidade ocidental. Porém, a

\footnotetext{
${ }^{16}$ ROCHA, 2008. P.10-2

${ }^{17}$ ANDRADE..2008.p.6

${ }^{18}$ Ibid
}

(C) 2008. Departamento de Direito da UFSM. Todos os direitos reservados. 
OUA não se manifestou tendo sempre como motivos os dois princípios (não-ingerência e soberania) ${ }^{19}$.

$\mathrm{Na}$ verdade, a preocupação dos chefes de Estados Africanos era com a unidade Africana e não-ingerência nos assuntos internos, a libertação não só do sistema colonial, mas também neocolonial. Esta é a critica que se faz à Organização da Unidade Africana (OUA), que seria a institucionalização de sindicato dos presidentes Africanos. A despeito disso, segundo um grande jurista nigeriano, a OUA declinou nessa direção porque, na sua criação, as promessas feitas por chefes de estados como, por exemplo, alta qualidade de vida, na qual haveria lugares para as pessoas morarem, emprego, não foram cumpridas e a maioria de destes povos careciam de tais direitos básicos ${ }^{20}$. Na verdade, esta situação se permanece ate hoje. Os direitos humanos eram utilizados como "pactum Saliens" na luta contra o colonialismo e a Apartheid e estes direitos não tinham proteção por parte desses Estados, ao contrário dos que os lideres preconizavam, antes de assumir o poder, como o respeito à dignidade da pessoa humana e o fortalecimento da luta pela independência. ${ }^{21}$

\section{1- OUA e a Proteção e Promoção dos Direitos Humanos}

Após a Segunda Guerra Mundial, a situação política no continente africano mudou consideravelmente, haja vista a aquisição da independência de seus Estados, processo ocorrido, principalmente, durante os anos 60 e 70. A Independência destes Estados deu oportunidade ao estabelecimento de uma organização regional, nos moldes já existentes em outros continentes; e que, como suas análogas, teve papel fundamental no desenvolvimento da proteção dos direitos humanos - apesar da diversidade, muitas vezes, de objetivos e métodos utilizados ${ }^{22}$.

Em 1979, o presidente Jimmy Carter, como parte da política externa norteamericana, iniciou a "cruzada pelos direitos humanos". Os outros países ocidentais começaram a condicionar os países que recebiam ajuda, para que respeitassem os direitos dos homens e a ONU promoveu eventos que chamaram atenção para a

\footnotetext{
${ }^{19}$ ANDRADE, 2008.p.7

${ }^{20}$ Ibid., p.5

${ }^{21}$ Ibid. , p.06

22 Ibid. ,p.3.
}

(C) 2008. Departamento de Direito da UFSM. Todos os direitos reservados. 
necessidade de se concertar um sistema regional próprio para proteção de direitos humanos no continente ${ }^{23}$.

Isso levou os Estados Africanos à conclusão de que, com a falta de uma boa interpretação ou erosão dos princípios de não-ingerência e soberania, tornaria inviável falar-se de um sistema de promoção e proteção dos direitos humanos eficaz. Foram estes entraves superados, por fim, pela OUA, que deram surgimento à carta africana dos direitos humanos e dos povos ${ }^{24}$.

Assim, Continente Africano estabeleceu um sistema regional de proteção dos direitos humanos. Após a descolonização, os Estados começaram a (Re) construção e (Re) estruturação (na verdade, se reconstrói o que foi construído; como não foi construído nada, a não ser ao contrario, os Estados começaram a construir e estruturar). Porém, para se chegar a um sistema Africano de proteção de tais direitos, havia um longo caminho a ser percorrido pela então Organização da Unidade Africana (OUA), que hoje se denomina União Africana (UA) ${ }^{25}$.

As grandes atrocidades cometidas pelos Estados vizinhos ou da região fez com que, em 1978, uma resolução movida pela Nigéria fosse adotada na sessão da Comissão dos Direitos Humanos da ONU, com o objetivo de pedir a ONU a assistência para o estabelecimento de instituições regionais de direitos humanos. Posteriormente, em 1979, nos dias 17 a 20, em Monrovia (Libéria), o presidente Leopoldo Sedar Senghor de Senegal propôs uma resolução que levou à decisão 115/XVI (1979). Esta tinha como objetivo a preparação de um esboço preliminar de uma Carta Africana dos Direitos Humanos e dos Povos, a qual vislumbrava o estabelecimento de um órgão para promoção e proteção de direitos dos homens ${ }^{26}$.

De 28 de novembro a 8 de dezembro de 1979, grupos de peritos reuniram-se com o intuito de preparar um esboço preliminar da Carta Africana. Eles se surpreenderam ao se deparar com o esboço, feito com antecedência, pelo secretário da OUA, a qual era semelhante com os dispositivos das convenções Européias e Americanas dos direitos humanos. No entanto, a consultoria jurídica da OUA e o grupo de peritos concluíram que OUA necessitava de um instrumento de direitos humanos diferentes e especiais, a qual lidasse especificamente com problemas Africanos e que

\footnotetext{
${ }^{23}$ ANDRADE, op. Cit. ,p.06

${ }^{24}$ Ibid. ,p.07

${ }^{25}$ Ibid.,p.4

${ }^{26}$ Ibid., p.08
}

(C) 2008. Departamento de Direito da UFSM. Todos os direitos reservados. 
tivesse como ênfase direitos e deveres dos povos e obrigações pertinentes à segurança do Estado e aos métodos para sua aplicação ${ }^{27}$.

Em 1980, de 09 a 15 de junho, esta Carta foi aprovada em Banjul (Gâmbia) e foram adotados apenas 11 artigos, que vieram a ser aderidos e retificados pelos Estadosmembros, somente em 1981. Entrou em vigor em 21 de outubro de $1986^{28}$.

Superados os conceitos tradicionais de soberania e não-ingerência, mesmo assim, os Estados continuam a violar tais direitos. Segundo Rocha (2008 p.9) ${ }^{29}$, "o que era para direito internacional clássica questão de guerra e da paz, passou a se consolidar como um direito voltado à cooperação, ao associativismo e à solidariedade, conjugando uma variedade de normas políticas, econômicas, cientificas, tecnológicas, social e cultural e cada vez mais vem buscando a construção de normas que compõem o direito internacional dos direitos humanos".

Assim sendo, a soberania passou a ter caráter limitado e subordinado ao direito internacional, em que os Estados são responsabilizados no plano internacional, em caso de violência dos direitos humanos ${ }^{30}$

\section{2- Divisões da Carta africana e Seu Caráter Normativo}

A Carta esta está dividida em três partes após seu preâmbulo: Dos Direitos e Deveres, das Medidas de Salvaguarda e Disposições Diversas.

O preâmbulo tem como dispositivo norteador as especificidades dos problemas Africanos dos direitos humanos. Com isso, a Carta adota dispositivos semelhantes aos vários instrumentos internacionais, sem esquecer a tradição Africana. A Carta, no seu caráter normativo, elenca alguns dispositivos que não se encontram nos instrumentos internacionais, como o seu art. 28, que reza que os indivíduos devem respeitar seus semelhantes sem nenhuma discriminação; e no seu art. $2^{\circ}$, ao incluir, entre os motivos

\footnotetext{
${ }^{27}$ Ibid., p.9

${ }^{28}$ Ibid., p. 9

${ }^{29}$ ROCHA, 2008

${ }^{30}$ Ibid. ,p.9
}

(C) 2008. Departamento de Direito da UFSM. Todos os direitos reservados. 
de não discriminação a distinção étnica. Tudo isso é devido ao caráter peculiar do Continente ${ }^{31}$.

Por outro lado, este documento não faz menção à clausula de derrogação, além de possibilitar o controle externo quanto à pertinência da violação ou suspensão dos direitos, em circunstância de guerra ou emergência. Para alguns autores, essa cláusula é um tipo de salvaguarda ${ }^{32}$.

A grande novidade desta Carta está em afirmar que os povos são também os titulares de direitos humanos, tanto no plano interno como na esfera internacional. Vale vislumbrar que um povo não deve ser confundido com minoria étnica, religiosa ou lingüística, apesar de que cada povo tem a sua cultura, o seu modo de vida. Por isto, seria necessário que cada sistema se adequasse ao modo de vida de cada povo. Nesse diapasão, Comparato (2003, p. 393) ${ }^{33}$ salienta que "o termo povo pode assumir três sentidos conforme o contexto: ele pode significar toda a população de uma colônia ou território; a totalidade dos cidadãos de determinado Estado; ou um grupo minoritário (...)".

Outros fatores de suma importância da Carta foram à necessidade de se dar importância ao principio de não-discriminação; de se enfatizar os princípios e objetivos da OUA; de demonstrar de que a moral e valores Africanos ainda têm significância nesta sociedade; de destacar também os direitos econômicos, sociais e culturais ${ }^{34}$.

Por outro lado, devido à peculiaridade de cada cultura, Dallari $\left(2004\right.$, p.13) ${ }^{35}$ traz que:

Os grupos sociais têm a sua própria cultura, que é condição natural e social, e as pessoas que vivem nos grandes centros urbanos terão o modo de agir e pensar diferente das pessoas que vivem nas savanas. Desse modo, mesmo com essas diferenças, todos os seres humanos têm o mesmo direito e deverão ser tratados como tal, o que não acontece na prática e o tratamento dado aos indivíduos diferentes decorre da existência dos direitos fundamentais iguais para todos.

Para isso, é importante respeitar os valores e as peculiaridades de cada cultura, como preconizam os relativistas.

\footnotetext{
${ }^{31}$ ANDRADE.2008.p.11

${ }^{32}$ Ibid. , p. 12-3

${ }^{33}$ COMPARATO, 2003.

${ }^{34}$ ANDRADE, op. Cit. , p.11

${ }^{35}$ DALLARI, , 2004
} 


\section{4- Direito ao Desenvolvimento}

O período colonial significou a diminuição, senão a extinção, por completo do exercício dos direitos humanos. Não havia respeito nem aos direitos civis e políticos, tampouco aos econômicos, sociais e culturais. Não houve, no geral, preocupação, por parte dos Estados colonizadores, quanto ao Desenvolvimento econômico de suas colônias - pelo menos até o início da segunda Grande Guerra, quando as exigências do Estado de beligerância forçaram uma consideração mais racional de seus recursos ${ }^{36}$.

Entretanto, o artigo $1^{\circ}$ da declaração da ONU, de 04 de dezembro de 1986 afirma que "O direito ao desenvolvimento é um direito humano inalienável, por força do qual todas as pessoas humanas e todos os povos estão autorizados a participar do desenvolvimento econômico, social, cultural e político, para dele contribuir e dele usufruir",37

O processo integral do desenvolvimento engloba vários fatores, não só o elemento político, mas também as realizações da vida democrática podem considerar como peça-chave deste processo. Igualmente, o desenvolvimento se dá através de políticas públicas ou programas de ação governamentais ${ }^{38}$.

Nesta ótica, a falta de menção da democracia na Carta Africana deve ser criticada. O processo de desenvolvimento não é um resultado natural do livre jogo das forças de mercado, mas deve ser planejado e dirigido pelos poderes públicos, com participação do povo ${ }^{39}$.

A despeito disso, Comparato (2003, pp. 396-397) $)^{40}$ :

Propõe a nova representação própria para o povo, deixando assim o velho sistema de legislativo e executivo, por estes serem a grande dificuldade para efetivação de um direito ao desenvolvimento; além destes apontam também como sendo segunda dificuldade a ausência quase completa de mecanismos jurídicos de garantia, que seria criar métodos de controle judicial de políticas públicas ou programas de ação governamental para tais fins.

\footnotetext{
${ }^{36}$ ANDRADE.2008, p.16-7

${ }^{37}$ Art. $1^{\circ}, \S 3^{\circ}$ da Carta das Nações Unidas, a expressão "direito ao desenvolvimento", necessariamente implica em uma atividade. Desta maneira, deve ser prevista a cooperação dos países desenvolvidos e países em desenvolvimento, fundamentada no conceito de justiça econômica distributiva

${ }^{38}$ ANDRADE, Op. Cit. ,p.16

${ }^{39}$ ANDRADE, Op. Cit. , p. 11

${ }^{40}$ COMPARATO, 2003.
}

(C) 2008. Departamento de Direito da UFSM. Todos os direitos reservados. 
A Carta Africana dos Direitos dos Povos é a primeira convenção internacional a afirmar o direito à preservação do equilíbrio ecológico e apresenta como condição do desenvolvimento nacional a tese do desenvolvimento sustentável.

A crítica que se faz a este diploma, segundo mesmo autor citado supra (2004 p. $398)^{41}$ :

É em relação à segurança e democracia, pois ela limita-se a indicar alguns casos de abusos individuais. Teria sido mais eficaz, para reforçar o alcance desse dispositivo, indicar, no plano interno a ligação essencial entre a segurança e o regime democrático e impor a preservação da paz externa, mecanismos de controle do comercio de armamentos, bem como inspeção internacional sobre os gastos militares, com a obrigação incondicional de se recorrer à arbitragem em caso de conflito.

Os Estados Africanos têm direito a autodeterminação das suas riquezas e dos seus recursos. Por conseguinte, inseriu-se na Carta o direito ao desenvolvimento, que até agora maioria destes Estados não está atingindo. Devido ao egoísmo dos chefes de Estados e militares, vários países mergulharam em Guerras como no Caso de GuinéBissau, Serra Leoa, Angola e muitos outros ${ }^{42}$.

Não obstante, os países desenvolvidos almejam que o direito ao desenvolvimento seja concedido aos países que sofreram a dominação colonial estrangeira e este direito encontra guarida na referida carta. O componente econômico do direito de desenvolvimento não deve prevalecer sobre os demais, pois não é crescimento econômico que reflete no desenvolvimento. $\mathrm{O}$ direito ao desenvolvimento demanda uma globalização ética e solidária ${ }^{43}$.

No entender de Bedjaqui (1991), apud Piovesan (2006, p. 20) ${ }^{44}$ :

A dimensão internacional do direito ao desenvolvimento é nada mais que o direito a uma repartição eqüitativa concernente ao bem-estar social e econômico mundial, pois reflete uma demanda crucial de nosso tempo, na medida em que quatro quintos da população mundial não mais aceitam o fato de $1 / 5$ da população mundial continua a construir suas riquezas com base em sua pobreza. Assimetrias globais revelam que a renda do $1 \%$ mais rica supera a renda dos $57 \%$ mais pobres na esfera mundial.

O desenvolvimento há de ser concebido como um processo de expansão das liberdades reais que as pessoas podem usufruir, segundo a concepção de Sen (2003 apud Piovesan (2006, p.21) ${ }^{45}$.

\footnotetext{
41 Ibid..

${ }^{42}$ ANDRADE, op. cit., p.16

${ }^{43}$ ANDRADE, op. Cit. , p.17

${ }^{44}$ PIOVESAN, 006.
}

(C) 2008. Departamento de Direito da UFSM. Todos os direitos reservados. 
Por fim, acrescenta-se ainda que a Declaração de Viena, de 1993 enfatiza ser o direito ao desenvolvimento um direito universal e inalienável, parte integral dos direitos humanos fundamentais ${ }^{46}$.

\section{4- CONSIDERAÇÕES FINAIS}

A Carta Africana dos Direitos Humanos e dos Povos, como todo instrumento relativo aos direitos humanos, traz consigo uma mescla de fatores jurídicos e políticos, os quais, dependendo do contexto, podem servir a distintos propósitos.

O que o povo Africano espera alcançar é a paz e uma proteção e promoção dos direitos humanos eficaz. Para se conseguir isso, muitos obstáculos hão de ser ultrapassados, tendo em vista a precariedade dos Estados Africanos, principalmente sua situação econômica, que restringe o trabalho destes e que acaba influenciando as Comissões dos Direitos Humanos, que têm de exercer suas competências dentro de uma margem muito estreita de flexibilidade, além de ter que usar como parâmetro disposições caracterizadas pela retórica. Com uma boa promoção e proteção dos direitos humanos mais a vontade política e tolerância por parte dos Chefes de Estados, pode-se possibilitar a existência da paz, fazendo com que os investidores, tanto nacionais como internacionais, tenham segurança de investir. Com isso e muitos outros fatores, este continente começará a descobrir os caminhos para o desenvolvimento, no qual os Estados vão conseguir dar uma vida digna para suas populações, libertando o povo dos males dos seus lideres, que lutaram para libertação dos Estados do jugo colonial e agora não querem a liberdade dos seus povos. Parece que só se libertaram dos estrangeiros (homens brancos), mas tudo está praticamente como era na época colonial, em que não havia respeito nem aos direitos civis e políticos, tampouco aos econômicos, sociais e culturais, existindo tal situação até hoje na África.

\footnotetext{
${ }^{45}$ PIOVESAN, 2006.

${ }^{46}$ Art. $2^{\circ}$ - Levando em consideração a situação particular dos povos submetidos à dominação colonial ou outras formas de dominação estrangeira, a Conferência Mundial sobre Direitos Humanos reconhece o direito dos povos de tomar medidas legítimas, em conformidade com a Carta das Nações Unidas, para garantir seu direito inalienável à autodeterminação. A Conferência Mundial sobre Direitos Humanos considera que a negação do direito à autodeterminação constitui uma violação dos direitos humanos e enfatiza a importância da efetiva realização desse direito.
}

(C) 2008. Departamento de Direito da UFSM. Todos os direitos reservados. 
Apesar dos problemas que comporta, a Carta de Banjul e seu Protocolo devem ser vistos como uma moção providencial, um passo na direção correta, rumo a um futuro democrático, onde serão reconhecidos e protegidos tanto os direitos individuais quanto os direitos dos povos, desejo de um povo sofrido, para a qual a palavra liberdade sempre é uma utopia.

\section{BIBLIOGRAFIA}

COMPARATO, Fabio Konder. A afirmação histórica dos direitos humanos. 3. ed. rev. ampl. São Paulo: Saraiva, 2003.

DALLARI, Dalmo de Abreu. Direitos humanos e cidadania. 2. ed. Reform. São Paulo: Moderna, 2004 (Coleções Polêmica).

JERÔNIMO, Patrícia. Os direitos do homem à escala das civilizações. Coimbra: Editora Livraria Almedina, 2001.

MOLLER, Josué Emilio. A fundamentação ético-politica dos direitos humanos. 2. ed. Curitiba: Juruá, 2007.

PIOVESAN, Flavia (coord.) Direitos humanos. Curitiba: Juruá, 2006.

\section{REFERENCIAS ELETRÔNICAS}

ANDRADE. José H. Fischel. A proteção dos direitos humanos e dos povos na África. Disponível em: <http://www.dhnet.org.br/direitos/sip/a_pdf/andrade_ protecao_dh_povos_africa.pd,> Acesso em: 08.mar.2008.

ROCHA, Patrícia Barcelos Nunes de Mattos, Direitos humanos e Globalização. Disponível em: <http://www.fdc.br/Revista/..\%5CArquivos\%5CRevista\%5C21/01. pdf.> Acesso em: 23.abr.2008. 